\title{
Pseudevernia furfuracea (L.) Zopf Likeninin Antibakteriyel Aktivitesi ve Antioksidan Kapasitesinin Araştırılması
}

\author{
Assessment of Antibacterial Activity and Antioxidant Capacity in Lichen Pseudevernia \\ furfuracea (L.) Zopf
}

\author{
Sinem GÜLTEKİN(D) 1 Gülşah ÖZYİĞiTOĞLU(D22 \\ ${ }^{1}$ Marmara Üniversitesi, Fen Bilimleri Enstitüsü, Biyoloji Anabilim Dalı, Kadıköy/Istanbul, TÜRKIYE. \\ ${ }^{2}$ Marmara Üniversitesi, Fen Edebiyat Fakültesi, Biyoloji Bölümü, Kadıköy/İstanbul, TÜRKIYYE.
}

öz

Bir mantar (mikobiyont) ve bir yeşil algin ve/veya siyanobakterinin (fotobiyont) bir araya gelmesiyle oluşan likenler; bu ortak yaşam sonucunda kendilerine özgü sekonder metabolitler üretirler. Yapılan araştırmalarda likenlerin bu sekonder metabolitler sayesinde çeşitli biyolojik aktivitelere ve antibakteriyel etkilere sahip oldukları bildirilmektedir. Bu çalışmada bir epifitik (ağaç üzerinde yetişen) dalsı liken Pseudevernia furfuracea (L.) Zopf türüne ait örneklerden elde edilen aseton ekstrelerinin ATCC 29212 Enterococcus faecalis, ATCC 25923 Staphylococcus aureus, CECT 4122 Pseudomonas aeruginosa, ATCC 25922 Escherichia coli suşları üzerindeki antibakteriyel aktiviteleri disk difüzyon yöntemi ile araştırılmıştır. Ayrıca aynı liken ekstrelerinin antioksidan kapasiteleri Bakır (II) İndirgeyici Antioksidan Kapasite (CUPRAC) metodu kullanılarak değerlendirilmiştir. P. furfuracea aseton ekstrelerinin antibakteriyel aktiviteleri Gram negatif bakterilere karşı etkisiz olurken Gram pozitif bakterilerin gelişimini inhibe etmiştir. Antioksidan olarak ise 9,653 $\pm 0,102 \mu \mathrm{g}$ TE/gr değerinde hesaplanan yüksek düzeyde kapasite göstermiştir. Doğadan elde edilmiş olan P. furfuracea likeninin farmakoloji alanında aktif olarak kullanılabilecek potansiyele sahip olduğu görülmektedir.

Anahtar Kelimeler: Liken, Pseudevernia furfuracea, antibakteriyel aktivite, antioksidan kapasite, sekonder metabolit

\begin{abstract}
Lichens are formed by the combination of a fungus (mycobiont) and a green alga and / or a cyanobacterium (photobiont), and as a result they produce unique secondary metabolites. Studies have shown that lichens have various biological and antibacterial effects due to these secondary metabolites. In this study, an antibacterial activity of acetone extracts from an epiphytic (growing on tree) fruticose lichen Pseudevernia furfuracea (L.) Zopf were investigated by disk diffusion method against ATCC 29212 Enterococcus faecalis, ATCC 25923 Staphylococcus aureus, CECT 4122 Pseudomonas aeruginosa and ATCC 25922 Escherichia coli strains. Also antioxidant capacities of the same extracts were assessed by Cupric Reducing Antioxidant Capacity (CUPRAC) method. According to the results obtained, the antibacterial activities of $P$. furfuracea acetone extracts were ineffective against Gram negative bacteria but inhibited the development of Gram positive bacteria. In addition, a high level of antioxidant activity was calculated with a value of $9.653 \pm 0.102 \mu \mathrm{g}$ TE / gr. It is seen that $P$. furfuracea has a potential to be used as a natural resource in the field of pharmacology.
\end{abstract}

Keywords: Lichen, Pseudevernia furfuracea, antibacterial activity, antioxidant capacity, secondary metabolite

\section{GiRiş}

Likenler en az bir mantar türü ile bir fotosentetik yeşil alg ve/veya siyanobakterinin mutualist birliktelikleri ile oluşan ortakyaşar organizmalardır. Liken birliklerinde mantar; yaşamını sürdürmek, büyüyebilmek ve üreyebilmek için gerekli olan karbon kaynağı olarak algi kullanırken alg, fotosentezde kullanacağı su ve minerali mantardan sağlamasının yanında, fiziksel 
olarak olumsuz koşullara karşı da mantar tarafından korunur $[1,2]$. Bu ortak yaşam sonucunda likenler, kendisini oluşturan mantar veya alg ortağına hiç benzerlik göstermeyen, yepyeni özellikler gösterirler.

Ekstrem koşullarda likenin fotosentez gibi fizyolojik olaylarının yavaşlaması sonucu büyümeleri de çok yavaş olmaktadır. Likenler, çok yavaş üremelerinden kaynaklanan rekabette zayıf kalma dezavantajlarını, ürettikleri özel maddeler sayesinde telafi ederler. Metabolizmaları sonucu açığa çıkan ve antimikrobiyal etkiye sahip bu maddeler likene özgü olup izole haldeki mantar ve algde bulunmamaktadır [3, 4]. Liken sekonder metabolitlerinin birçok biyolojik aktiviteye sahip olduğu çok sayıda araştırmayla ortaya konulmuştur. Bu çalışmalardan bir kısmı likenlerin antibakteriyel $[5,6]$, antioksidan $[7,8]$, antiviral [9], bir kısmı antitümöral [10], antiinflamatuar [11] gibi çeşitli biyolojik aktivitelere sahip olduğunu göstermektedir. Eski ve yeni literatürde likenler, "soğuk algınlıkları, barsak kurtlarının düşürülmesi, kuduz, ateşli hastalıklar, humma nöbetleri, alerji, cilt hastalıkları, sarılık, boğmaca, solunum yolu hastalıkları, öksürük ve kemik kırıklarının" tedavisinde; balgam söktürücü olarak ve laksatif amaçıı kullanımlarının yanında, damar küçültücü olarak da kan akışı engellenmesinde kullanımları ile kayıtlıdır.

Likenler sentezledikleri sekonder metabolitleri çevresel koşullara uyum sağlama ve savunma aracı olarak kullanılırlar [12]. Bu metabolitlerin özellikle Gram pozitif bakteriler üzerinde Gram negatif bakterilere oranla daha etkili olduğu ve bazı mantarlara karşı antagonist aktivite gösterdiği bildirilmiştir [13]. Gram negatif bakterilerin daha duyarsız olma sebebi amfipatik ya da hidrofobik moleküllere daha az geçirgen olan bir dış membrana sahip olması ile açıklanmıştır [14].

En diş yörüngede eşleşmemiş elektrona sahip moleküller olarak tanımlanan "serbest radikaller" vücutta normal metabolik reaksiyonlar sonucu ya da sigara ve alkol kullanımı, hava kirliliği, bazı ilaçlar ve radyasyona maruz kalma gibi nedenlerle oluşabilirler $[\mathbf{1 5}, \mathbf{1 6}]$. Gıdalarda veya vücutta düşük derişimlerde bulunduğunda bir hedef molekülün oksidatif hasarını geciktiren, engelleyen veya ortadan kaldıran maddeler antioksidanlar olarak tanımlanmaktadır. Antioksidan özellikteki maddeler serbest radikallerin lipitlere, proteinlere veya DNA ya verebileceği zarara karşı bir savunma kalkanı niteliğindedir [17]. Bu zarar veya hasarlar kalp hastalıkları, şeker hastalığı, damar sertliği gibi çeşitli ciddi hastalıklara sebep olabilmektedir [18]. Serbest radikallerin etkisiz duruma getirilmesi dokuların bu hasarlardan korunabilmesi için önemlidir. Çeşitli bitkilerden elde edilmiş karotenoidler, fenoller, askorbik asit ve azotlu bileşikler doğal kaynaklı antioksidanlardır [5]. Bu bilgilere dayanarak son yıllarda likenlerin de antioksidan kapasitelerinin araştırıldığ çalışmalar artmaya başlamışıtır $[6,8,19]$.

Dalsı liken türü Pseudevernia furfuracea, bir koruyucu olarak (sabun, kozmetik kokuları gibi) ve besleyici olarak (ekmek yapımında) tarih boyunca işlenmiştir [20]. Bu çalışmada $P$. furfuracea liken örneklerinin antibiyotik ve antioksidan kapasite potansiyelinin belirlenmesi amaçlanmıştır.

\section{MATERYAL VE YÖNTEM}

\section{I. Liken aseton ekstrelerinin hazırlanması}

Bursa ili Alaçam bölgesinden toplanan liken örnekleri Pseudevernia furfuracea (L.) Zopf olarak tayin edilmiştir. Tanımlaması yapılan liken örnekleri yıkanıp kurumaya bırakılmış, kuruyan likenler porselen havanda parçalanarak toz haline getirilmiştir. Toz halindeki örnekler hassas terazi ile ölçüm alınarak steril falkonlara doldurularak üzerlerine 35 $\mathrm{ml}$ (mililitre) aseton ilave edilmiştir. Liken sekonder metabolitleri için iyi bir çözücü olarak bilinmesinden dolayı liken ekstreleri aseton ile hazırlanmıștır. Hazırlanan falkon tüpler 24 saat boyunca 1şık görmeyen ortamda beklemeye bırakılmıştır. Bekleme süresi bittikten sonra Whatman No.1 filtre kağıdından geçirilerek Soxhlet ekstraktörü yardımıyla asetonun büyük bir kısmı uçurulup, kalan asetonun da uçması için steril cam petrilere alınarak 24 saat çeker ocakta bekletilmiştir. Asetonun uçmasıyla cam petrilerde kalan liken ekstreleri kazınarak steril ependorflara konulmuş ve deneyde kullanılmak için uygun şartlarda muhafaza edilmiştir.

\subsection{Test bakterilerinin hazırlanması}

Test edilen bakteriler, Enterococcus faecalis (ATCC 29212), Staphylococcus aureus (ATCC 25923), Pseudomonas aeruginosa (CECT 4122) ve Escherichia coli (ATCC 25922), Yeditepe Üniversitesi Merkez Mikrobiyoloji Laboratuvarı'ndan temin edilmiştir.

Luria Bertoni (LB) besiyerinde prosedürlere uygun olarak çoğaltılan bakteri suşları 1 gece boyunca $37^{\circ} \mathrm{C}$ ' de inkübe edilmiştir. UV-VIS Spektrofotometre ile bakteri konsantrasyonları 0,5 McFarland'a ayarlanmıştır.

\subsection{Disk difüzyon testi}

P. furfuracea türüne ait liken örneklerinden elde edilen ekstrelerden hassas terazide 13,8 mg ölçülerek 1462,5 mikrolitre $(1,4625 \mathrm{ml})$ asetonda çözdürülmüştür. $9 \mathrm{mg} / \mathrm{ml}$ konsantrasyona sahip olan ekstreler $6 \mathrm{~mm}$ çapındaki steril disklere önce bir yüzeye $10 \mu \mathrm{l}$ eklenilmiş ve asetonun uçması beklenildikten sonra steril diskin diğer yüzüne de 10 
$\mu \mathrm{l}$ ekstre eklenilmiştir. İşlem $20 \mu \mathrm{l}, 40 \mu \mathrm{l}$ ve $80 \mu \mathrm{l}$ dozlarını elde edene kadar yapılmıştır. 0,5 McFarland konsantrasyonundaki bakterilerden $35 \mu$ alınarak steril cam baget ile LB Agar besi yerlerine yayılarak hazırlanmış petrilere hazırlanan diskler uygun mesafelerde ve üç doz olacak şekilde yerleștirilmiştir. Karşılaştırma amaçli; E. faecalis ve S.aureus suşlarının yayıldığı besi yerlerine Sulphamethoxazole $25 \mu \mathrm{g}$, P. aeruginosa ve E. coli suşlarının olduğu besi yerlerine ise Ciprofloxacin $5 \mu \mathrm{g}$ antibiyotik diski yerleştirilmiştir. Kontrol amacı ile aseton emdirilmiş diskler de hazırlanmış ve tüm petriler $37^{\circ} \mathrm{C}$ 'de inkibasyona bırakılmıştır. İnkübasyon sonunda petrilerde bulunan disklerde inhibisyon zonu oluşup olmadığ kontrol edildikten sonra inhibisyon zonuna sahip disklerin ölçümleri cetvel ile yapılarak kaydedilmiştir. Deney üç tekrarlı olarak çalışılmış ve sonuçlar ortalama değerler hesaplanarak bulunmuştur.

\subsection{Antioksidan kapasite testi}

Apak ve ark. (2004) tarafından geliştirilen CUPRAC (Bakır (II) İndirgeyici Antioksidan Kapasite) yöntemi kullanımıştır [21].

CUPRAC yöntemi için; 1,0 x 10-2 $\mathrm{M} \mathrm{CuCI}_{2}$. $2 \mathrm{H}_{2} \mathrm{O}$ ve $1,0 \mathrm{M}$ amonyum asetat $250 \mathrm{ml}$ distile su, 1,0 $\mathrm{M}$ neocuproine $50 \mathrm{ml}$ etanol içerisinde çözdürülmüştür. Antibakteriyel aktivite deneyi ile ayn konsantrasyonda $(9 \mathrm{mg} / \mathrm{ml})$ olacak şekilde toz liken ekstreleri asetonda çözülmüştür. Hazırlanan üç solüsyondan 50 şer $\mu 1$ alınarak cam tüpe konulduk$\tan$ sonra üzerine $55 \mu$ l liken ekstresi konulmuştur. Kontrol grubu olarak üç solüsyona liken ekstresi yerine $55 \mu \mathrm{l}$ aseton konulmuştur. İyice çalkanan tüpler ağzı kapatılarak oda sıcaklığında 30 dakika bekletilmiştir. 30 dakikalık bekleme süresinin ardından örnekler UV spektrofotometrede $450 \mathrm{~nm}$ absorbansta ölçülmüştür. Troloks referans antioksidan olarak kullanılmış ve elde edilen verilerin standart sapmaları ve ortalamaları belirlenmiştir. Deneyler üç tekrarlı olacak şekilde yapılmıştır.

\section{BULGULAR}

\section{I. Antibakteriyel aktivite}

Disk difüzyon ile elde edilen antibakteriyel aktivite sonuçları Tablo 1'de gösterilmiştir. Zon ölçümleri ortalama değerlerine göre, en yüksek antibakteriyel etki $S$. aureus üzerinde, en yüksek doz olan $80 \mu l$ P. furfuracea aseton ekstresinin emdirildiği diskte $18 \mathrm{~mm}$ olarak ölçülmüştür. Disklere emdirilen ekstre miktarının azalması ile birlikte zon çaplarının da küçüldüğü görülmüştür. Gram pozitif bakterilere karşı belli oranda inhibisyon zonu oluştururken Gram negatif bakterilerin olduğu besi yerlerinde disk etrafinda herhangi bir zon oluşmadığı gözlemlenmiştir.

Tablo I. Pseudevernia furfuracea aseton ekstrelerinin inhibisyon zonlar1

\begin{tabular}{|l|l|l|l|l|l|}
\hline \multirow{2}{*}{ BAKTERİ SUŞU } & \multicolumn{5}{|l}{ İNHİBİSYON ZONLARI (mm) } \\
\cline { 2 - 6 } & $20 \mu \mathrm{l}$ & $40 \mu \mathrm{l}$ & $80 \mu \mathrm{l}$ & CIP 5 $\mu \mathrm{g}$ & SXT 25 $\mu \mathrm{g}$ \\
\hline $\begin{array}{l}\text { Enterococcus faeca- } \\
\text { lis (ATCC 29212) }\end{array}$ & $15 \pm 1$ & $16 \pm 1$ & $17 \pm 0.7$ & $\mathrm{D}$ & $26 \pm 0.6$ \\
\hline $\begin{array}{l}\text { Staphylococcus au- } \\
\text { reus (ATCC 25923) }\end{array}$ & $16 \pm 0.7$ & $17 \pm 0.7$ & $18 \pm 0.7$ & $\mathrm{D}$ & $26 \pm 1$ \\
\hline $\begin{array}{l}\text { Pseudomonas aeru- } \\
\text { ginosa (CECT 4122) }\end{array}$ & - & - & - & $32 \pm 0.6$ & $\mathrm{D}$ \\
\hline $\begin{array}{l}\text { Escherichia coli } \\
\text { (ATCC 25922) }\end{array}$ & - & - & - & $25 \pm 0.6$ & $\mathrm{D}$ \\
\hline
\end{tabular}

* Rakamlar mm olarak inhibisyon zonlarının çaplarını ifade etmektedir. Her disk $6 \mathrm{~mm}$ çapındadır.

Sonuçlar yapılan üç deneyin ortalamasını göstermektedir. (-): inhibisyon yok, (D): denenmedi

\section{I. Antioksidan kapasite}

P. furfuracea liken aseton ekstresinin antioksidan kapasitesi CUPRAC yöntemi ile test edilmiştir. Bu yöntemde antioksidan kapasite, 2,9 dimetil-1,10-fenantrolin (Neokuproin-Nc)'in $\mathrm{Cu}(\mathrm{II})$ ile oluşturduğu bakır(II)-neokuproin kompleksinin (Cu(II)-Nc), 450 nm'de maksimum absorbans veren bakır(I)-neokuproin $[\mathrm{Cu}(\mathrm{I})-\mathrm{Nc}]$ kelatına indirgenme yeteneğinden yararlanarak hesaplanmaktadır.

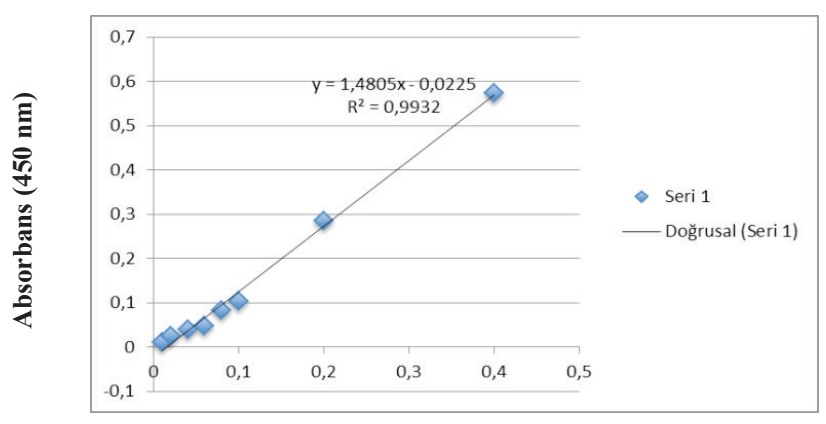

Konsantrasyon (mg/ml)

Şekil I. Liken aseton ekstresinin Bakır (II) İndirgeyici Antioksidan Kapasitesi

CUPRAC karışımı $P$. furfuracea ekstresi ve kontrol grubu olarak aseton ilave edilerek ölçüm yapılmış ve $P$. furfuracea'ya ait grupta antioksidan kapasitesine bağlı olarak sarı renk oluşumu gözlemlenmiştir. Troloks çözeltisinden alınan hacime bağlı $\mathrm{ml}$ bazındaki absorbans değerleri ölçülerek troloks kalibrasyon grafiği çıkarılmış ve grafikteki 
troloks etkinliği ile $P$. furfuracea aseton ekstrelerinin etkinlikleri oranlanmıştır (Şekil 1). Sonuç olarak P. furfuracea ekstrelerinin CUPRAC yöntemi ile ölçülen antioksidan değeri; 9,653 $\pm 0,102 \mu \mathrm{g}$ TE/gr olarak hesaplanmıştır.

\section{TARTIŞMA VE SONUÇ}

Likenlerin yaşamlarını sürdürebilmelerinde liken maddelerinin rolü büyüktür. Yetiştikleri habitatlarda kendilerini mikroorganizmalara, böceklere, radyasyona, vb. etkilere karşı koruyabilmeleri için sekonder metabolitleri ürettikleri birçok yayında belirtilmiştir $[2,4,14,22]$.

Likenlerin kendilerine özgü ürettikleri bu sekonder metabolitler sayesinde çeşitli biyolojik aktiviteler gösterdikleri bilinmektedir. Bu çalışmada incelenen Pseudevernia furfuracea likeninden atrarik asit $[8,23]$, atranorin $[8,24]$, fisodik asit, oksifisodik asit, fisodalik asit, virensik asit [24], kloratranorin, metil hematomat, metil klorohematomat [23], absisik asit, poliaminler (putresin and spermidin) [25] ve furfurik asit [26] gibi metabolitler elde edilmiştir. P. furfuracea (var. ceratea) likeninin aseton ekstresinden izole edilen olivetorik asitin güçlü anti-anjiyogenik aktivite sergilediği ve bununla birlikte diklorometan, aseton ve metanol ekstreleri arasında en yüksek antioksidan kapasitesinin aseton ekstresinde olduğu rapor edilmiştir [27].

$\mathrm{Bu}$ çalışmada, ülkemizdeki ormanlarda geniş yayılış gösteren dalsı ağaç likeni P. furfuracea aseton ekstrelerinin, ikisi Gram pozitif ikisi Gram negatif olan 4 bakteriye karşı disk difüzyon yöntemiyle antibakteriyel aktivitesi ve bunun yanında CUPRAC yöntemi ile antioksidan kapasitesi incelenmiştir. Çözücü olarak asetonun tercih edilmesinin nedeni asetonun liken içindeki sekonder metabolitler için iyi bir çözücü olduğunun literatürde sıklıkla kaydedilmesidir [25, 26, 27]. Bakterilere karşı inhibisyon aktiviteleriyle ilgili çalışmalarda test edilecek olan liken ekstrelerinin hazırlanmasında kullanılan farklı çözücülerin farklı metabolitleri aktif hale getirdikleri görülmüştür. Nitekim, liken sekonder metabolitleri ve likenlerin biyolojik aktiviteleriyle ilgili çok sayıda çalışmadan oluşan güncel bir derlemede; likenlerin türlerine, sekonder metabolit içeriklerine ve yetiştikleri ortama bağlı olarak değişen oranlarda antimikrobiyal etkiler gösterdikleri ve bununla birlikte kullanılan çözücü ya da yöntemsel farklılıkların da etkinlik düzeylerini etkilediği bilgisi verilmiştir [22].

Çeşitli liken türlerinin antibakteriyel etkinliklerinin test edildiği birçok yayın bulunmaktadır. Ancak likenlerin biyolojik aktivite seviyeleri türe göre değiştiğinden, burada özellikle çalışmamızdaki ile aynı liken türünü (P. furfuracea) içeren çalışmaların sonuçları karşılaştırılmıştır. Yine de liken türleri veya kullanılan yöntemler bakımından farklılık göstermeleri nedeniyle bazı çalışmaların sonuçlarının karşılaştırılmaları güç olmaktadır. Bu çalışmada antibakteriyel etkileri bakımından test edilen liken aseton ekstreleri, Gram negatif bakteriler üzerinde herhangi bir inhibe edici etki göstermezken, Gram pozitif bakterilere karşı orta seviyede antibakteriyel etki göstermişlerdir. Bununla birlikte antioksidan kapasite testi sonucu oldukça yüksektir.

Osmanağaoğlu ve ark. (2000) tarafından P. furfuracea var. furfuracea ve Evernia divaricata likenleri ile yapılan çalışmada, aseton ve kloroform liken ekstreleri Gram pozitif çomak ve koklar, Gram negatif çomaklar ve Candida albicans üzerinde disk difüzyon yöntemiyle test edilmiştir. Çalışmamızla benzer olarak, sadece Gram pozitif bakterilerde inhibisyon zonları görülürken Gram negatif bakterilerde herhangi bir etki görülmemiştir. Ayrıca çalışmada çözücü olarak aseton kullanımının kloroform kullanımına göre daha büyük çaplarda inhibisyon zonu oluşumu sağladığı sonucuna varılmıştır [28].

Mitrovic ve ark. (2014) tarafindan Platismatia glauca ve P. furfuracea liken türlerinin antimikrobiyal aktivitesi üzerine yapılan araştırmada, altı Gram pozitif ve beş Gram negatif bakteri suşu ile çalışılmış ve farklı çözücülerde gösterdikleri etkileri karşılaştırılmıştır. Her iki liken türünün de benzer bakterilere etki gösterdiği fakat $\mathrm{P}$. furfuracea’ nın daha yüksek antimikrobiyal etkisi olduğu belirtilmiştir. $P$. furfuracea' nın metanol ekstresinin, diğer çözücülere k1yasla, $S$. aureus üzerinde daha güçlü etkili olduğunu göstermişlerdir. Buna göre P. furfuracea likeni için metanolün asetondan daha iyi bir çözücü olduğu düşünülebilir. İki çalışma arasında, aynı liken türü için dahi (P. furfuracea), toplandığ bölgeler, antimikrobiyal aktivitede kullanılan yöntem (mikrodilüsyon) ve kullanılan çözücüler bakımından farklılıklar bulunduğu görülmektedir [8].

P. furfuracea türüne ait farklı ekstrelerin çeşitli mikroorganizmalar üzerindeki antimikrobiyal aktivitelerinin belirlenmesi amacıyla Gücin ve ark. (1997) tarafından yapılan bir başka çalışmada, Gram negatif bakterilere karşı hiçbir etki olmazken Gram pozitif bakterilerden S. aureus, S. epidermidis ve B. subtilise karşı tüm ekstrelerde antibakteriyel etki saptanmıştır. Elde ettikleri sonuçlar çalışmamızla paralellik göstermektedir [5].

Güvenç ve ark. (2012) tarafından P. furfuracea üzerinde disk difüzyon ile yapılan diğer bir çalışma ise çalışmamızı destekler nitelikte sonuçlara sahiptir. Buna göre E. coli üzerinde etki göstermeyen ekstrelerin Gram pozitif mikroorganizmalara karşı belirgin aktivite gösterdiği gözlemlenmiştir. Ancak metanol, etil asetat ve diklorometan ekstrelerinin kullanılması nedeniyle çözücü bakımından çalışmamız ile farklidir [23]. 
P. furfuracea likeninin antioksidan kapasitesiyle ilgili pek az çalışma bulunmaktadır. Örneğin $P$. glauca ve $P$. furfuracea türlerinin güçlü antioksidan kapasiteye sahip olduğu kaydedilen Mitroviç ve ark. (2014)'ın çalışmasında yöntem bakımından farklılıklar bulunmaktadır. Çalışmada su ve metanol ekstreleri radikal süpürücü kapasite yöntemi olan (-Difenil-1-pikrihidrazil) DPPH ile değerlendirilmiştir [8]. Yine Güvenç ve ark. (2012) tarafindan P. furfuracea üzerinde DPPH yöntemiyle fakat farklı çözücülerle yapılan antioksidan kapasite çalışmasında metanol ekstrelerine göre daha düşük bulunmuştur [23].

Odabaşoğlu ve ark. (2005)'nın çalışmasında ise P. furfuracea metanol ektresinin toplam fenolik içeriğinin yüksek olmasına rağmen antioksidan kapasitesinin düşük olduğu sonucu elde edilmiştir [29].

Sarıkürkçü ve ark. (2016) tarafindan P. furfuracea metanol ve su ekstrelerinin in vitro antioksidan kapasiteleri ve enzim önleme faaliyetlerinin değerlendirildiği bir çalışmada yine metanol ekstrelerinin hem fenolik hem de flavonoid bileşikler bakımından zengin olduğu kaydedilmiştir. Çalışmamızda kullandığımız aseton ekstrelerinden farklı olarak, bu çalışmalarda metanol ile hazırlanmış olan P. furfuracea ekstrelerinin belirgin olarak daha yüksek antioksidan kapasiteye sahip olduğu gösterilmiştir [19].

Biyolojik aktivite üzerine yapılan çeşitli in vitro çalışmalar, likenlerin bazı doğal ve deneysel faktörlere bağlı olarak değişen oranlarda antibakteriyel etkileri ve antioksidan kapasiteleri olduğunu ortaya koymaktadır. Ülkemizde doğal yayılışı çok olan $P$. furfuracea likeninin antibakteriyel ve antioksidan etkilerinin araştırıldığı bu çalışma ise, likenin toplandığı yer ve aseton çözücü kullanılması nedeniyle diğerlerinden farklılık göstermektedir. Aynı liken üzerine yapılan diğer çalışmaların sonuçları, uygulanan yöntemlerdeki farklılıklara bağlı olarak değişmektedir. Bununla birlikte bu liken türünün genel anlamda hem antibakteriyel hem antioksidan potansiyele sahip olduğunu söylemek mümkündür.

Bu çalışma, seçilen türün geleneksel tıbbi kullanıma sahip olması ile ve aseton ekstrelerinin test edilmesi yönüyle diğer çalışmalardan ayrılmaktadır. Çalışmamızın doğal bitkisel kaynaklarımız olan likenlerden alternatif antibiyotik ve antioksidan olarak yararlanılabilmesine katkı sağlayabileceği düşünülmektedir.

\section{TEŞEKKÜR}

Çalışma sürecinde laboratuvar imkanı sağlayan Doç. Dr. N. Cenk SESAL'a ve deney aşamasındaki yardımları için Ezgi UÇARKUŞ ile Barış GÖKALSIN' a teşekkür ederiz.

\section{KAYNAKLAR}

[1] Nash III, TH. (1996). Lichen Biology, Cambridge: Cambridge University Press.

[2] Dayan, F. E., \& Romagni, J. G. (2001). Lichens as a potential source of pesticides. Pesticide Outlook, 12(6), 229-232.

[3] Harmala, P., Hiltunen, R., Oksman-Caldentey, K. M., Laakso, T., \& Kauppinen, V. (1992). Isolation and in vitro cultivation of lichen algae and their antimicrobial properties. Fitoterapia, 63, 217-225.

[4] Lawrey, J. D. (1986). Biological role of lichen substances. Bryologist, Volume 89(2), 111-122.

[5] Gücin, E., Dülger, B. Aslan, A. (1997). Pseudevernia furfuracea (L.) Zopf. Likeninin Antimikrobiyal Aktivitesi, Ekoloji-Çevre Dergisi, 7(25), 22-24.

[6] Öztürk, Ş..Güvenç, Ş., (1995). Farklı Bölgelerden Toplanan Liken Örneği Pseudevemia furfuracea (L.) Zopf. var. furfuracea' nın Antimicrobiyal Etkilerinin Karşılaştırılması. Tr. J. of Botany, 19, 145-148.

[7] Velioglu, Y. S., Mazza, G., Gao, L., \& Oomah, B. D. (1998). Antioxidant activity and total phenolics in selected fruits, vegetables, and grain products. Journal of agricultural and food chemistry, 46(10), 4113-4117.

[8] Mitrovic, T., Stamenkovic, S., Cvetkovic, V., Radulovic, N., Mladenovic, M., Stankovic, M., ... \& Comic, L. (2014). Platismatia glaucia and Pseudevernia furfuracea lichens as sources of antioxidant, antimicrobial and antibiofilm agents. EXCLI journal, 13, 938.

[9] Neamati, N., Hong, H., Mazumder, A., Wang, S., Sunder, S., Nicklaus, M. C., ... \& Pommier, Y. (1997). Depsides and depsidones as inhibitors of HIV-1 integrase: discovery of novel inhibitors through 3D database searching. Journal of medicinal chemistry, 40(6), 942-951.

[10] Demleitner, S., Kraus, J., \& Franz, G. (1992). Synthesis and antitumour activity of derivatives of curdlan and lichenan branched at C-6. Carbohydrate research, 226(2), 239-246.

[11] Süleyman, H., Yildirim, D., Aslan, A., Göçer, F., Gepdiremen, A., \& Güvenalp, Z. (2002). An Investigation of the Antiinflammatory Effects of an Extract from Cladonia rangiformis HOFFM. Biological and Pharmaceutical Bulletin, 25(1), 10-13.

[12] Huneck, S. (1999). The significance of lichens and their metabolites. Naturwissenschaften, 86(12), 559-570.

[13] Culberson W., L. (1970). Chemosystematics and ecology of lichens-forming fungi. Ann Rev Ecol Sys, 1, 153-70.

[14] Lawery, J. D. (1989). Lichen secondary Compounds Evidence for a Correspondence Between Antiherbivore and Antimicrobial Function. Bryologist, 92(3), 326-328.

[15] Machlin, L. J., \& Bendich, A. (1987). Free radical tissue damage: protective role of antioxidant nutrients. The FASEB Journal, 1(6), 441-445.

[16] Fang, Y. Z., Sheng, Y., WU, G. (2002). Free Radicals, Antioxidants, and Nutrition, Nutrition. Department of Biochemistry 
and Molecular Biology, Beijing Institute of Radiation Medicine, Beijing, China. Oct; 18, 872-879.

[17] Halliwell, B., \& Gutteridge, J. M. (2015). Free radicals in biology and medicine. Oxford University Press, USA.

[18] Valko, M., Leibfritz, D., Moncol, J., Cronin, M. T., Mazur, M., \& Telser, J. (2007). Free radicals and antioxidants in normal physiological functions and human disease. The international journal of biochemistry \& cell biology, 39(1), 44-84.

[19] Sarikurkcu, C., Kocak, M. S., Calapoglu, M., Ocal, C., \& Tepe, B. (2016). Biological and phytochemical evaluation: Pseudevernia furfuracea as an alternative multifunctional agent. Journal of Functional Foods, 24, 11-17.

[20] Joulain, D., \& Tabacchi, R. (2009). Lichen extracts as raw materials in perfumery. Part 2: treemoss. Flavour and Fragrance Journal, 24(3), 105-116.

[21] Apak, R., Güçlü, K., Özyürek, M., \& Karademir, S. E. (2004). Novel total antioxidant capacity index for dietary polyphenols and vitamins $\mathrm{C}$ and $\mathrm{E}$, using their cupric ion reducing capability in the presence of neocuproine: CUPRAC method. Journal of agricultural and food chemistry, 52(26), 7970-7981.

[22] Özyiğitoğlu, G. Ç., Açıkgöz, B., \& Sesal, C. (2016). Lichen secondary metabolites: Synthesis pathways and biological activities. Acta Biologica Turcica, 29(4), 150-163.

[23] Güvenç, A., Akkol, E. K., Süntar, İ., Keleş, H., Yıldız, S., \& Çalış, İ. (2012). Biological activities of Pseudevernia furfuracea (L.) Zopf extracts and isolation of the active compounds. Journal of ethnopharmacology, 144(3), 726-734.

[24] Proksa, B., Adamcova, J., Sturdikova, M., \& Fuska, J. (1994). Metabolites of Pseudevernia furfuracea (L.) Zopf. and their inhibition potential of proteolytic enzymes. Die Pharmazie, 49(4), 282-283.

[25] Unal, D., Senkardesler, A., \& Sukatar, A. (2008). Abscisic acid and polyamine contents in the lichens Pseudevernia furfuracea and Ramalina farinacea. Russian journal of plant physiology, 55(1), 115-118.

[26] Gunzinger, J., \& Tabacchi, R. (1985). Isolement et identification de l'acide furfurique, nouvelle depsidone du lichen Pseudevernia furfuracea (L.) Ach. Helvetica chimica acta, 68(7), 1936-1939.

[27] Koparal, A. T., Ulus, G., Zeytinoğlu, M., Tay, T., \& Türk, A. Ö. (2010). Angiogenesis inhibition by a lichen compound olivetoric acid. Phytotherapy research, 24(5), 754-758.

[28] Osmanağaoğlu, Ö., Yıldız, A., \& Saçılık, S. (2000). Türkiye'deki farklı bölgelerden izole edilen likenlerin antimikrobiyal aktiviteleri. Türk Mikrobiyol. Cem. Derg, 30, 17-19.

[29] Odabasoglu, F., Aslan, A., Cakir, A., Suleyman, H., Karagoz, Y., Bayir, Y., \& Halici, M. (2005). Antioxidant activity, reducing power and total phenolic content of some lichen species. Fitoterapia, 76(2), 216-219. 